\title{
Article \\ Combining the Multilevel Perspective and Socio-Technical Imaginaries in the Study of Community Energy
}

\author{
Natalia Magnani ${ }^{1, *(D)}$ and Valentina-Miriam Cittati ${ }^{2}$ \\ 1 Department of Sociology and Social Research, University of Trento, Via Verdi 26, 38122 Trento, Italy \\ 2 Institute for Renewable Energy, Eurac Research, Viale Druso 1, 39100 Bolzano, Italy; \\ valentinamiriam.cittati@eurac.edu \\ * Correspondence: natalia.magnani@unitn.it
}

check for updates

Citation: Magnani, N.; Cittati, V.-M. Combining the Multilevel Perspective and Socio-Technical Imaginaries in the Study of Community Energy. Energies 2022, 15, 1624. https://doi.org/10.3390/ en15051624

Academic Editor: Ben McLellan

Received: 28 December 2021 Accepted: 10 February 2022 Published: 22 February 2022

Publisher's Note: MDPI stays neutral with regard to jurisdictional claims in published maps and institutional affiliations.

Copyright: (C) 2022 by the authors. Licensee MDPI, Basel, Switzerland. This article is an open access article distributed under the terms and conditions of the Creative Commons Attribution (CC BY) license (https:// creativecommons.org/licenses/by/ $4.0 /)$.

\begin{abstract}
The current paper contributes to the literature on community renewable energy by considering two projects developed in the north-west of Italy, in the Piedmont region. Community renewable energy is increasingly regarded by academic literature and policy discourse as crucial to ensure a socially and environmentally just energy transition. In spite of the growing diffusion of community renewable energy projects, there is still a lack of theoretically informed analyses. Our article tries to address this gap by combining two theoretical perspectives: the multilevel perspective and the socio-technical imaginaries approach. Applying the first perspective helps reconstruct the context and circumstances that have permitted the Piedmont's energy community projects to emerge. Particular attention is given to the windows of opportunity created by the Regional Law 12/2018, which acknowledged the establishment of energy communities for the first time in Italy. The socio-technical imaginaries perspective allows the identification of collective ideas and meanings that emerge when individuals or groups promote a socio-technical innovation. Based on this analysis, three main future changes are associated with community renewable energy: an integral ecology approach, a stronger sense of community, and a local development opportunity for rural areas characterised by depopulation, a low employment rate, and high energy demand.
\end{abstract}

Keywords: community renewable energy; socio-technical imaginaries; multilevel perspective; energy transition

\section{Introduction}

Increasing research has focused on community renewable energy projects (CREs) as an alternative social and ecological solution to climate change. CREs can be defined as formal or informal initiatives activated by citizens which propose collaborative solutions to facilitate the development of energy sustainability technologies on a regional basis [1]. As Walker [2] has previously highlighted, these projects can take diversified organisational and legal forms: from cooperatives owning energy infrastructure, and non-profit entities managing the plants on behalf of the local community, to co-ownership of green energy projects by communities, businesses and local governments. CREs can function as energy producers or suppliers, or combine these areas to promote energy-saving projects. Moreover, they can be based on local communities or communities of interest [3,4].

Sociological literature [3,5-8] generally agrees in attributing economic, social and environmental advantages to CREs that distinguish them from governmental or company-led initiatives. In particular, scholars [9] have suggested the potential of CRE in democratising renewable energy production. Recently, the importance of the CRE model for fostering the energy transition has also been formally acknowledged by the European Commission, which, with the Clean Energy Package and specifically with Directive 2018/2001, for the first time introduced regulatory provisions to regulate this socio-technical innovation [10].

In the academia, CRE is an emerging research field in which descriptive accounts prevail, whereas theoretical references are still quite limited and fragmentary. 
Our paper aims to contribute to an emerging theoretically informed literature, by applying the multilevel and socio-technical imaginaries perspectives to two case studies of CRE. Key questions we aim to answer in our article are the following:

- What are the factors that favoured the emergence of the CRE projects?

- How did local promoters and civil society understand and envision the establishment of CREs?

The current study shows how recent important changes at the regime level, such as the transposition of the European Directive 2018/2001 (RED II), push relevant changes at the regional level. In addition, the socio-technical imaginaries perspective, applied for the first time to CRE, is beneficial in highlighting the micro-processes of cognitive construction involved in the initial development of a socio-technical innovation. The proposed study is innovative not only at a theoretical level, but also at an empirical one. Magnani and Osti [3] highlighted that studies on CRE have tended to focus on northern-central European countries and the United States, with little attention paid to southern European countries, although they are affluent in renewable energy sources. This paper addresses this gap in the literature by focusing on two case studies from Northern Italy.

The remainder of the article is organised as follows. Section 2 provides a literature review for both the multilevel perspective (MLP) (Section 2.1) and the socio-technical imaginaries approach (Section 2.2). Section 3 illustrates the research method and the case studies regarding two CRE projects in the Italian region of Piedmont. Section 4 is dedicated to the analysis of the case studies according to the two theoretical approaches above. In particular, Section 4.1. focuses on the empirical application of MLP to the analysis of the structural conditions favouring the development of the two case studies. Section 4.2 empirically applies the socio-technical imaginaries approach to the analysis of discourses and representations emerging around the two CRE projects. Section 4.3 analyses CRE case studies as a mix of alternative and dominant imaginaries. Finally, Section 5 draws some conclusions resulting from the combination of the two theoretical perspectives to case studies of CRE.

\section{Literature Review}

\subsection{The Multilevel Perspective (MLP)}

The MLP is an analytical approach used to study the dynamics of innovations in sociotechnical transitions [11]. It is centred on the identification of three interacting analytical levels: the landscape (macro-level), the regime (meso-level) and the niche (micro-level) [12]. The first level represents the contextual environment and consists of the processes and factors (e.g., macroeconomics, macropolitics and societal structures) that influence people within society. Usually, those processes are long-lasting, meaning they change very slowly over time (e.g., climate change, demographic shifts) [13]. The landscape produces significant transformations in the regime and the niche, although its effects are evident only over a long period.

The regime consists of the official rules, institutions and technologies that affect social groups' activities. Some examples are technical elements (e.g., resources and grid infrastructures), regulations, behavioural norms and guiding principles. Scholars agree that regimes are characterised by lock-in and path dependency, namely, they follow predictable mechanisms and trajectories that prevent changes [14]. However, external factors can pressure a regime and create unexpected transformations, opening windows of opportunity for innovation.

Niche actors may take advantage of these changes and nurture novelties, such as new technologies. Consequently, the niche starts acting like an 'incubator', where innovations emerge, protected from external economic influences and pressure in the existing system until new changes happen. All three layers are interdependent, which means that an event occurring at one level affects the other levels, thus generating disadvantages and/or opportunities for niche actors. 
Several studies have adopted the MLP to understand how energy transition occurs in society, identifying the niche level as an incubator of innovations and its actors as promoters of technological and social novelties. Among the research investigating renewable technology, Carstens and Da Cunha [15] studied the emergence of solar photovoltaic electricity in Brazil, describing the current status of renewable energy and growth opportunities. By employing the MLP, they observed how the three levels influence each other, stressing that photovoltaic development at the niche level positively influenced landscape factors such as education, employment and economic performance. However, they demonstrated that technology development (niche) is also affected by governmental initiatives such as photovoltaic policies and entrepreneurial activity (regime).

Another study focusing on multilevel influences investigated the diffusion of solar electricity in the United States [16]. It showed how the niche emerged in the late 1950s from NASA research on photovoltaics that explored reliable 'off-grid' electricity to power satellites. The existing socio-technical regime encompassed 'the existing energy generation and transmission system, the massive political and lobbying power of conventional fossil energy corporations, and significant, longstanding public subsidies to non-renewable energy' [16] (p. 148). The landscape effects were identified mainly with the 1970s OPEC oil embargo, which significantly stimulated government and business interest in renewable energies.

Hölsgens et al. [17], by studying five projects selected among the top social innovations for the Energiewende in North Rhine-Westphalia, stressed that the MLP is especially useful for those cases where social innovation leads to system transformations and has a clear competing or symbiotic relationship with the existing regime.

Finally, specifically regarding the application of the MLP to CREs, Doci et al. [18] compared four energy communities in the Netherlands, exploring them as a particular type of grassroots initiative with the potential to foster the energy transition. They argued that different actors foster renewable initiatives with heterogeneous motivations and diverse technologies. Focusing their analysis on the social dimension of sustainability, the researchers stressed that CREs are social niches that introduce social innovations in the electricity market (regime-level), creating new energy production practices and autonomous ways to manage energy problems, in addition to supporting social groups.

\subsection{The Sociotechnical Imaginaries Perspective}

Researchers define the concept of imagination $[19,20]$ as a social practice that can help individuals visualise the possible futures to which they aspire [21]. Individuals may project their visions towards material objects, which become vehicles for new and different meanings by imagining possible futures. For example, individuals may project onto technology (i.e., renewable energy) their expectations of inclusion and participation, which acquire social meanings different from the original purpose (i.e., from reducing carbon emissions to increasing democracy). In this regard, Jasanoff and Kim [21] elaborated the concept of socio-technical imaginaries as 'collectively imagined forms of social life and social order reflected in the design and fulfilment of nation-specific scientific and/or technological projects' [21] (p. 120). Accordingly, by employing technologies, individuals may imagine new forms of society to meet their needs and improve their living standards. In doing so, technology becomes a vehicle of sense and the means through which people fulfil their aspirations.

Usually, socio-technical imaginaries originate from a single individual's vision, which is shared with others and, whether or not it is accepted, becomes a collective imaginary aimed at creating forthcoming possibilities of progress [22]. Socio-technical imaginaries can influence the decisions of states towards the expected futures they wish to implement. In addition to national states, other groups such as 'corporations, social movements and professional societies' can envisage socio-technical imaginaries and decide to enforce them by fostering a specific technology [22]. Socio-technical imaginaries result from individuals who share visions, so they can also be employed to enhance public involvement and, thus, used as a democratic tool [23]. 
Although it takes time to create socio-technical imaginaries and benefit from them, they play a socially valuable role in supporting technology, particularly those related to renewable energy. In this regard, scholars have employed the socio-technical imaginaries perspective to investigate the collective ideas linked to the adoption of renewable technology, focusing on risks and benefits derived from energy choices [24] and on how national visions drive desirable collective futures [21]. For instance, Ballo [25] investigated the energy imaginaries of a forthcoming smart grid in Norway promoted by a network of experts. He argued that national imaginings partially pervade the futures of the smart grid, which are primarily linked to technological and economic outcomes. Among the benefits, the smart grid was imagined to manage the uncertainties caused by nature and solve possible social issues deriving from a lack of communication with the public.

Some studies have placed particular stress on heterogeneity and differentiation in the production of socio-technical imaginaries around energy. Longhurst and Chilvers [26], for example, mapped and compared 12 visions produced across the state, business, science and technology, and civil society in the UK. By analysing similarities and differences, the researchers identified two types of socio-technical imaginaries: the dominant and the alternative. The former emphasises large-scale technological change, issues focused on the energy trilemma - climate change, energy costs and security-and an economic model based on development and progress (i.e., new jobs, wealth creation). Usually, the state, market, and science and technology are more likely to support dominant imaginaries. Civil society, however, tends to produce visions associated with alternative imaginaries, highlighting the importance of social and cultural change, ethics, equity, environmental issues and a degrowth approach.

Both imaginaries identify climate change as an issue that needs to be tackled to reach energy transition and encourage the creation of a system based on renewable energies. Nonetheless, the two visions recommend managing energy transition interventions in different points of the system. The main difference between dominant and alternative imaginaries here is that the former supports the idea that economic development will lead to social development, whereas the latter argues that degrowth is necessary to achieve a just and sustainable energy transition. As we show in Section 4.3, this distinction between dominant and alternative imaginaries appears particularly relevant in our case studies.

\section{Methodology}

The present paper is based on a qualitative methodology centred around two case studies of CRE projects located in two mountain areas in the Piedmont region, in the northwest of Italy. The two case studies were selected because they were among the first projects of CRE developed in Italy. Moreover, the region Piedmont was the first region in Italy to pass a specific law on energy communities. Thus, the two cases are trailblazers for social innovation in the energy sector. A short description of the two case studies is provided here. The first case study, Pinerolo (Figure 1), is a rural town in the district of Turin with around 37,744 (2021) inhabitants, while the second case, Valle Maira (Figure 2), is a valley in the province of Cuneo containing 14 small municipalities with around 21,569 (2020-2021) total inhabitants. Both areas are characterised by depopulation, unemployment and brain drain. This led Valle Maira to be included in the National Strategy for Internal Areas (Strategia Nazionale Aree Interne, SNAI), which aims to improve citizens' quality of life by increasing wellness, social inclusion, extensive growth, labour demand and territorial capital. At the same time, Pinerolo supports the project 'Ripartiamo Insieme' (Restart together), which seeks to address the town's development issues, further worsened by the COVID-19 pandemic. In doing so, the project gathers different actors (local associations, municipalities, local companies, trade unions, Turin's chamber of commerce, Pinerolo's Diocese and the Waldensian Diaconia), which deliberate on territorial issues to find collective solutions. 


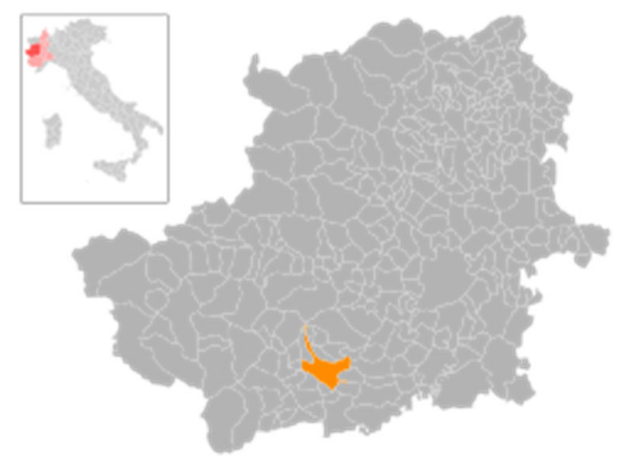

Figure 1. The town of Pinerolo in the province of Turin, Piedmont region.

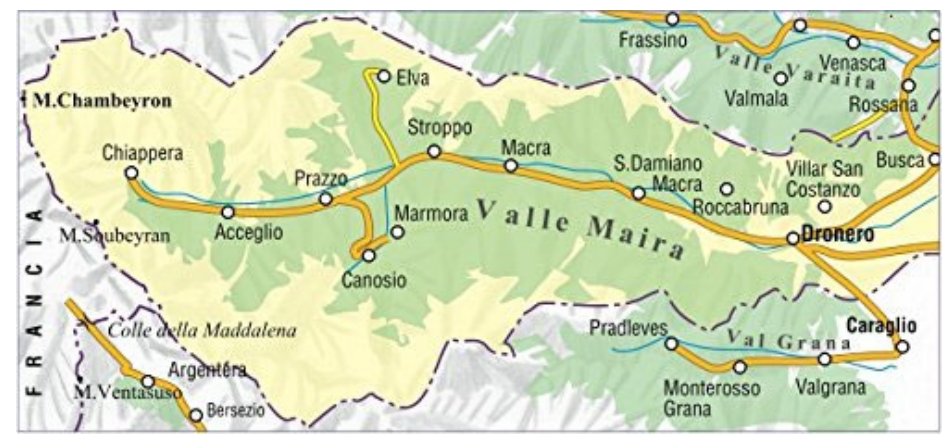

Figure 2. The Valley of Maira in the province of Turin.

Concerning the first case study, the main promoter of Pinerolo's CRE project was a professor from the Polytechnic of Turin. The Polytechnic of Turin is one of the members of a local consortium (Consorzio Pinerolese Energia, CPE) that has been created to promote a new local energy production and consumption system. The CPE gathers the Polytechnic of Turin, a local private-public utility Acea Pinerolese, six municipalities, five local companies and a number of associations, including the local trade union, the Catholic dioceses and the Waldensian Diaconia.

Concerning the second case study, the leading promoter of Valle Maira's CRE project is the local Mountain Union, including the nearby valley Valle Grana. Its forthcoming CRE will include 22 municipalities, the Mountain Union and its Department of Environment and Territory, a local mixed public-private utility (Maira S.p.A.) and the Agency of Vocational Education.

The study is based on 10 semi-structured interviews conducted online (due to the COVID-19 pandemic) between May 2020 and February 2021 with the promoters and civil society members involved in Pinerolo's and Valle Maira's CREs. For Pinerolo, the interviews included several members of the CPE: the professor from the Polytechnic of Turin (also promoter of the Regional Law), a representative of the local multi-utility Acea Pinerolese S.p.A., a representative of the local trade union (CGIL), Pinerolo's bishop and the president of the Waldensian Diaconia of the Valleys.

Regarding the case study in Valle Maira, the interviews involved the president of the Mountain Union, the director of the Environment and Territory Department of the Mountain Union, the president of Maira S.p.A. and the CEO of the Agency of Vocational Education, representing the forthcoming CRE's economic office.

Key questions that were asked during interviews concerned the existing institutional and regulatory framework that may or may not allow the fostering of a CRE, in addition to the visions that the local promoters wished to achieve through the implementation of CRE. In particular, through the interviews with the local promoters, four main themes were investigated: regulation, participation, environmental conservation and territorial innovation. Concerning the first theme, the interviewees explained the local and national 
regulatory barriers to their initiatives, and the solutions they have produced to overcome them. Concerning the second theme, the interviews examined the citizens' engagement strategy of promoters. As a third point, the importance of environmental conservation for the promoters was explored, and how the CRE project contributes to achieving it. Finally, the interviews explored the potential territorial innovation that the promoters aspire to promote through the implementation of the CRE project.

\section{Analysis}

\subsection{Application of the MLP to the Case Studies}

In the present paper, the three MLP levels analysed in Section 2.1 help understand the circumstances that have enabled Piedmont's CRE projects to emerge (Figure 3). Specifically, the macro-level consists of the climate crisis and its effects on natural and social dimensions. It also includes social changes, such as transformations in politics, culture, worldviews (e.g., globalisation, individualism) and economics. Among those changes, attempts have been made by most industrialised countries to address gas emissions through several political measures in recent decades (e.g., Our Common Future, Kyoto Protocol, Paris Agreement). The consequent worldwide demonstrations (e.g., Friday for Future) show an intense cultural transformation regarding the perception of production and consumption in contemporary society.

As an effect of the growing international interest in sustainability and the circular economy, the meso-level has experienced several changes over time. In particular, the EU member states introduced new regulations, laws, and subsidies favouring an energy system based on renewable technologies. Among the measures put into practice, RED II allows European citizens to establish CREs for producing, sharing and storing renewable energy. Moreover, in Italy, the National Energy Strategy (Strategia Energetica Nazionale, SEN) sets sustainability goals to improve competitiveness and decrease $\mathrm{CO}_{2}$ levels by 2030. To reach these objectives, the SEN advocates developing renewable energy resources, energy efficiency and energy security. In February 2020, Italy issued the Milleproroghe decree to preview the transposition of RED II, allowing Italian regions to build CREs. Before the RED II was adopted in December 2021, the Mille proroghe decree established a transitory regulation acknowledging and supporting-for the first time-renewable energy communities.

As a result of the regime's adjustments to the landscape, windows of opportunity emerge, and niche actors may pressure the existing rules and institutions by introducing innovations to meet their needs. This occurred in 2018 in Piedmont, with Regional Law $12 / 2018$, which allows the establishment of CREs at the region level. The promoter was a professor and environmentalist from the Polytechnic of Turin willing to foster a CRE in Pinerolo. Thanks to the Regional Law, the nearby members of the Mountain Union in Valle Maira also decided to plan a CRE based on renewable energy consumption and production.

Moreover, before the Regional Law was issued, in 2019, the CPE fostered the establishment of an oil-free zone in Pinerolo, which encourages the use of renewable energy technologies for decreasing $\mathrm{CO}_{2}$ emissions in the area and promotes an inclusive governance model on energy issues. To create the oil-free zone, local actors referred to the existing law 221/2015, which allows the establishment of an area reliant on natural resources to produce renewable energy. In doing so, they attempted to deal with the lack of a national law transposing the European Directive RED II. Currently, Pinerolo's oil-free zone represents the core of the forthcoming CRE.

Regarding energy production, Pinerolo's CRE will generate electricity from three sources: the local hydroelectric power plant called Inverso Pinasca; solar panels of varying sizes owned by companies, public actors and private citizens; and biomass and biogas from the waste produced by the oil-free zone. Pinerolo has already installed total power in power plants of $135.2 \mathrm{MW}$, of which $45 \%(60.4 \mathrm{MW})$ is derived from the hydroelectric power plant, 38\% (51 MW) from solar panels, 12\% (16.2 MW) from biomass and 5\% (7.6 MW) from biogas. By comparison, to produce energy for their CRE project, Valla Maira's actors intend 
to rely on three hydroelectric power plants (3.1 MW, 1.9 MW, and 0.45 MW, producing 1.5 MWh per year for Valle Maira), which will be owned by an association of purpose.

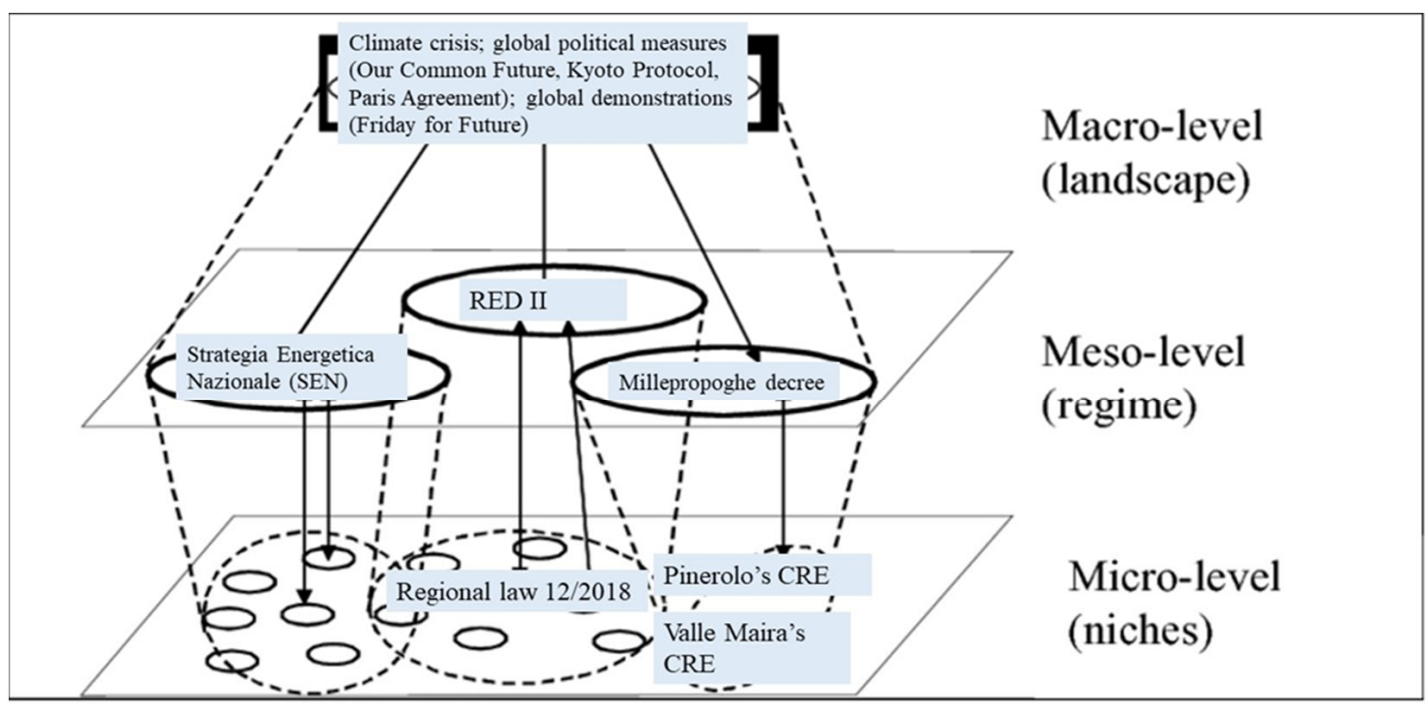

Figure 3. Application of the MLP to the case studies (our elaboration from [27]).

\subsection{Application of the Socio-Technical Imaginaries Approach to the Case Studies}

Although the MLP helps to analyse the broad context that allows socio-technical transitions to arise and identifies the niche level as the cradle of novelties, the sociotechnical imaginary perspective focuses specifically on the motivations behind technology promotion. It explains how niche actors decide to foster CRE projects for promoting renewable technologies in their territory. By creating collective imaginaries, individuals or social groups share visions of possible futures that innovations-including technologymay bring about.

In this paper, the socio-technical imaginaries perspective helps clarify why Pinerolo's and Valle Maira's actors encouraged CRE initiatives and what visions the stakeholders projected on renewable technologies. By analysing the 10 interviews with the promoters and members of the civil society in Pinerolo and Valle Maira, it was possible to identify three main futures that they imagine achieving with their CREs: a stronger connection between humans and nature (the 'integral ecology' concept), a sense of community, and territorial development that includes and supports the most vulnerable population groups.

\subsubsection{Integral Ecology}

To explain the motivation behind Valle Maira's CRE project, the Mountain Union's president referred to the concept of integral ecology as expressed by the Pope's encyclical 'Laudato si" (2015). Integral ecology is an invitation to an integral vision of life starting from the belief that everything in the world is connected, that we are interdependent on each other and dependent on Mother Earth. It shares the idea that the environment is a common good, thus, highlighting the importance of managing it in a way that is collectively beneficial and socially just for the present and future generations. On this basis, the Valle Maira Mountain Union president also stressed the role of the local community, which must become actively involved in environmental preservation projects. He stated:

My programme has a solid environmental connotation, which implies people's involvement rather than merely ecological protection. I refer to the Pope's Encyclical 'Laudato si", particularly to the 'integral ecology' concept [ ... ]. When I talk about protecting the environment, I mean that all of us are protagonists of this phase. 
Even Pinerolo's bishop stressed the importance of integral ecology for projects such as CREs. According to him, this concept addresses social inequalities that also characterise environmental conservation:

I think that the 'Laudato si" managed to put together different people and aspects of ecology, such as the importance of justice. The 'integral ecology' puts together environmental issues with social inequality and injustice, which are two aspects absolutely interconnected. For example, climate change and environmental catastrophes create poverty or, at least, increase injustices and social gaps.

\subsubsection{Sense of Community}

According to the bishop of Pinerolo, a key social problem characterises contemporary rural societies: people do not trust institutions and are reluctant to collaborate towards collective goals. However, he believes that it is still possible to restore a sense of community, and cooperation on energy issues among local actors can have a key role in that:

The community has collapsed, a sense of belonging to a community doesn't exist anymore $[\ldots]$. There is a distance between the individual and institutions, because the idea of a community to which people belong is missing. We need to rebuild the community in several ways. The CPE is pushing people to interact with each other. In this way, I believe that it will be possible to create a sense of belonging in Pinerolo by building something that makes us say proudly: I belong here.

\subsubsection{Local Development and Support for the Most Vulnerable Groups}

During the interviews, the actors from both Pinerolo and Valle Maira often mentioned the problems their rural territories typically suffer from, such as depopulation and unemployment. CRE projects were considered an opportunity for local development by fostering more attentive management of local energy resources, which could fuel also other rural activities. As argued by the professor from the Polytechnic of Turin:

We [Pinerolo's inhabitants] have problems like abandonment and irrational usage of local resources, for example energy. By enhancing good management of energy, it would be possible to encourage activities linked to the mountain such as agriculture, animal farming, etc., and improve local employment opportunities.

Valle Maira's promoters, such as the CEO of the Agency of Vocational Education, highlighted the benefits that a CRE project would bring to a disadvantaged territory, mainly through the promotion of self-sufficiency and a circular economy approach:

Our territory is sparsely populated and, although hydroelectric energy is certainly a fundamental resource, people are not conscious of its potential. For us [promoters of Valle Maira's CRE], the innovation of the CRE is fostering redistributive policies, a circular economy, and involving companies and inhabitants in a disadvantaged area by using energy as a common good. Therefore, for a disadvantaged area such as Valle Maira, innovation means having an advantage and becoming competitive by counting on local natural resources.

In addition to preventing further depopulation of the valley, for actors in Pinerolo, their CRE project also represents a driving force for other development initiatives concerning the entire local community, as the CGIL representative (i.e., from Pinerolo's trade union) claimed:

One benefit from creating a CRE might be transforming public transport into electric public transport, using the energy produced here. Another benefit might also be addressing vulnerable peoples' needs. I mean, we could produce and redistribute energy by decreasing the electricity bills for those persons who need help, and we could do so without additional costs to the community. 
Finally, the promoters are also convinced that their CRE may help develop their territories by creating new jobs, as the representative of the local company in Pinerolo, Acea Pinerolese S.p.A., claimed:

With the CRE project we aspire to create new relationships among the local companies that will join the project. We expect additional benefits such as creating green jobs.

\subsection{CREs as a Mix of Dominant and Alternative Imaginaries}

The distinction mentioned in the literature review (Section 2) between dominant and alternative socio-technical imaginaries appears especially useful to interpret the discourses examined here in relation to the two CRE projects. In particular, Table 1 illustrates the characteristics of the visions articulated around Pinerolo's and Valle Maira's CREs according to the variables proposed by Longhurst and Chilvers [26]. In relation to the overall trajectory, the importance of integral ecology as a concept emerges in guiding the willingness to support initiatives that encourage participation in sustainability and conservation of local natural resources. In this light, the CRE model helps to reframe the environment, and especially energy, as a common good, that needs to be collectively managed in the common interest.

Table 1. The visions of local actors from Pinerolo and Valle Maira on CRE projects (our elaboration from [26]).

\begin{tabular}{ccc}
\hline Element & Dominant Imaginaries & Alternative Imaginaries \\
\hline Overall trajectory & - & Integral ecology \\
\hline $\begin{array}{c}\text { Issues pertaining to the } \\
\text { Energy Transition }\end{array}$ & Lower electricity bills & $\begin{array}{c}\text { Support to the most vulnerable } \\
\text { population groups }\end{array}$ \\
\hline Underlying organizational logic & - & Cooperative form \\
\hline Relation to economic trajectory & $\begin{array}{c}\text { Territory's development and } \\
\text { tackling of depopulation, } \\
\text { unemployment }\end{array}$ & - \\
\hline
\end{tabular}

The issues pertaining to the energy transition show that the actors in Pinerolo and Valle Maira are motivated by both dominant and alternative imaginaries in fostering their CREs. These actors frame the energy transition around the energy costs, stressing the importance of ensuring lower electricity bills for the inhabitants as a benefit from their projects. In addition, they also focus on an energy transition that includes and supports the most vulnerable population groups by creating employment opportunities and addressing energy poverty in mountain areas. In relation to the underlying organisational logic, Pinerolo's actors' intention to legally establish a cooperative for their CRE project and Valle Maira's establishment of an association highlights a voluntaristic organisational logic typical of alternative imaginaries. In relation to the economic trajectory, rather than supporting a degrowth strategy, the actors stressed the importance of CRE projects in supporting local development through the circular economy and the creation of green jobs to tackle local issues such as depopulation and unemployment. They also envision their CRE as a driving force for other initiatives (i.e., electrical public transport) that can improve local services and environmental sustainability. The result of this analysis is a mix of elements from the alternative and dominant socio-technical imaginaries, reflecting the heterogeneity of the actors involved in the planning stage of the two CREs and the mixed ideas about how to implement an energy transition locally.

\section{Discussion and Conclusions}

The current paper analyses the CRE projects in Pinerolo and Valle Maira in the Italian region of Piedmont, combining insights from the MLP and socio-technical imaginaries perspectives. The combination of these two theoretical perspectives proved useful in unpacking the structural and cognitive dimensions involved in developing a collective 
socio-technical innovation such as a CRE. In particular, two research questions were addressed in the paper, namely: What are the factors that favoured the emergence of the CRE projects? How did local promoters envision the establishment of CREs? The MLP helped clarify the broad multilevel structural context in which the two CRE projects emerged. As mentioned above, essential at the regime level was the RED II, which acknowledges that European citizens can establish CREs to produce, share and store renewable energy. This change at the regime level has created new opportunities for niche actors interested in innovative ways to consume and produce renewable energy [27]. Due to pressure from civil society actors, Piemonte's Regional Law 12/2018 on CRE was the first to be proclaimed in Italy before the transposition of the RED II was issued at the national level. Based on the Regional Law, actors from Pinerolo and Valle Maira started fostering their CRE initiatives. Then, in 2020, the Milleproroghe decree made it urgent to legally define the CRE model in Italy. These results are in line with existing literature on MLP analysed in Section 2.1, which stresses how CREs are social innovations that mutually interact with the landscape [16] and with the regime level [17]. Moreover, our analysis confirmed that the creation of a network among a vast heterogeneity of actors (companies, experts, religious leaders, trade unions, etc.) is needed to develop innovative niches on renewable energy [18].

Although the MLP helped frame the context from which the two projects emerged, the socio-technical imaginaries perspective made possible the analysis of the collective cognitive dimension implied in developing CREs [21]. In particular, the actors in Pinerolo and Valle Maira associated three main socio-technical imaginaries with their CRE projects: the integral ecology concept, a stronger sense of community, and territorial development supporting the more vulnerable population groups. By employing the distinction of dominant and alternative imaginaries from Longhurst and Chilvers [26] analysed in Section 2.2, it was possible to identify the visions prevalent in Pinerolo and Valle Maira as mixed imaginaries. This seems to support the idea-advanced by some authors [28]—of CREs as boundary objects around which different visions and discourses coalesce. The concept of boundary objects [29] refers to socio-technical objects that can be differently interpreted by the actors involved, while having a core of shared meanings. This concept helps to clarify how different actors cooperate in a project despite their diverse interests and perspectives. It is exactly the ambiguous and open-ended character of CRE projects that may be crucial to favouring the widest diffusion of decentralised and democratic forms of energy production among different social groups and territories.

In our case studies, the institutional and regulatory framework represents an essential element that boosts the two renewable energy initiatives. Eventually, in December 2021, Italy adopted the European Directive 2018/2001. However, until now, the lack of a national regulation has prevented CREs from becoming a widespread model, leaving private citizens and local administrations of initiatives such as those of Pinerolo and Valle Maira as isolated, innovative exceptions. Nonetheless, the insights presented here may inspire policymakers interested in supporting renewable initiatives that valorise local resources and enhance civic engagement while addressing underdevelopment and marginalisation.

At this point, it is also important to acknowledge the limitations of this study. Although the present paper aimed to understand the collective imaginaries of the local actors, it mainly emphasised the promoters' visions. This is due to the early stage of development of the two CREs, which involved the main promoters and some prominent individuals from the civil society (e.g., religious leaders), but still need to engage the majority of local inhabitants. Future research might fill this gap by investigating whether ordinary citizens share the same imaginaries of promoters around technology and its social implications. In addition, researchers might also explore the process of translation of the socio-technical imaginaries analysed above in specific governance models for CRE and the methods used for citizens' engagement in practice, in order to understand whether they are in line with the democratic values encouraged by CRE advocates. 


\begin{abstract}
Author Contributions: Conceptualization, N.M. and V.-M.C.; methodology, V.-M.C.; investigation, V.-M.C.; writing — original draft preparation, N.M. and V.-M.C.; writing-review and editing, N.M. and V.-M.C. All authors have read and agreed to the published version of the manuscript.
\end{abstract}

Funding: This research received no external funding.

Informed Consent Statement: Informed consent was obtained from all subjects involved in the study.

Acknowledgments: We would like to thank Vincent Lagendijk for his support in structuring the research and Jessica Balest for her useful comments on an earlier version of this paper.

Conflicts of Interest: The authors declare no conflict of interest.

\title{
References
}

1. Bauwens, T.; Gotchev, B.; Holstenkamp, L. What drives the development of community energy in Europe? The case of wind power cooperatives. Energy Res. Soc. Sci. 2016, 13, 136-147. [CrossRef]

2. Walker, G. What are the barriers and incentives for community-owned means of energy production and use? Energy Policy 2008, 36, 4401-4405. [CrossRef]

3. Magnani, N.; Osti, G. Does civil society matter? Challenges and strategies of grassroots initiatives in Italy's energy transition. Energy Res. Soc. Sci. 2016, 13, 148-157. [CrossRef]

4. Tarhan, M. Renewable Energy Cooperatives: A Review of Demonstrated Impacts and Limitations. J. Entrep. Organ. Divers. 2015, 4, 104-120. [CrossRef]

5. Gubbins, N. Community Energy in Practice. Local Econ. J. Local Econ. Policy Unit 2007, 22, 80-84. [CrossRef]

6. Rogers, J.C.; Simmons, E.A.; Convery, I.; Weatherall, A. Social impacts of community renewable energy projects: Findings from a woodfuel case study. Energy Policy 2012, 42, 239-247. [CrossRef]

7. Seyfang, G.; Hielscher, S.; Hargreaves, T.; Martiskainen, M.; Smith, A. A grassroots sustainable energy niche? Reflections on community energy in the UK. Environ. Innov. Soc. Transit. 2014, 13, 21-44. [CrossRef]

8. Yildiz, Ö.; Rommel, J.; Debor, S.; Holstenkamp, L.; Mey, F.; Müller, J.R.; Rognli, J. Renewable energy cooperatives as gatekeepers or facilitators? Recent developments in Germany and a multidisciplinary research agenda. Energy Res. Soc. Sci. 2015, 6, 59-73. [CrossRef]

9. Van der Horst, D. Social enterprise and renewable energy: Emerging initiatives and communities of practices. Soc. Enterp. J. 2008, 4, 171-185. [CrossRef]

10. Grignani, A.; Gozzellino, M.; Sciullo, A.; Padovan, D. Community Cooperative: A New Legal Form for Enhancing Social Capital for the Development of Renewable Energy Communities in Italy. Energies 2021, 14, 7029. [CrossRef]

11. Shove, E.; Walker, G. Caution! Transitions ahead: Politics, practices, and sustainable transition management. Environ. Plan. 2007, 39, 763-770. [CrossRef]

12. Geels, F.W. The multi-level perspective on sustainability transitions: Responses to seven criticisms. Environ. Innov. Soc. Transit. 2011, 1, 24-40. [CrossRef]

13. Verbong, G.; Geels, F. Exploring sustainability transitions in the electricity sector with socio-technical pathways. Technol. Forecast. Soc. Chang. 2010, 77, 1214-1221. [CrossRef]

14. Dosi, G. Sources, procedures, and microeconomic effects of innovation. J. Econ. Lit. 1998, 26, 1120-1170.

15. Dos Santos Carstens, D.D.; da Cunha, S.K. Challenges and opportunities for the growth of solar photovoltaic energy in Brazil. Energy Policy 2018, 125, 396-404. [CrossRef]

16. Hinrichs, C.C. Transitions to sustainability: A change in thinking about food systems change? Agric. Hum. Values 2014, 31, 143-155. [CrossRef]

17. Hölsgens, R.; Lübke, S.; Hasselkuß, M. Social innovations in the German energy transition: An at-tempt to use the heuristics of the multilevel perspective of transitions to analyse the diffusion process of social innovations. Energy Sustain. Soc. 2018, 8, 8. [CrossRef]

18. Dóci, G.; Vasileiadou, E.; Petersen, A.C. Exploring the transition potential of renewable energy communities. Futures 2015, 66, 85-95. [CrossRef]

19. Appadurai, A. Modernity at Large: Cultural Dimensions of Globalisation; University of Minnesota Press: Minneapolis, MN, USA, 1996.

20. Fujimura, J.H. Future imaginaries: Genome scientists as sociocultural entrepreneurs. In Genetic Nature/Culture Anthropology and Science beyond the Two-Culture Divide; Goodman, A.H., Heath, D., Lindee, M.S., Eds.; University of California Press: Berkley, CA, USA, 2003; pp. 176-199.

21. Jasanoff, S.; Kim, S.-H. Containing the Atom: Sociotechnical Imaginaries and Nuclear Power in the United States and South Korea. Minerva 2009, 47, 119-146. [CrossRef]

22. Jasanoff, S. Future imperfect: Science, technology, and the imaginations of modernity. In Dreamscapes of Modernity: Sociotechnical Imaginaries and the Fabrication of Power; Jasanoff, S., Kim, S., Eds.; University Press Scholarship: Oxford, UK, $2014 ;$ pp. 1-33.

23. Barnett, J.; Burningham, K.; Walker, G.P.; Cass, N. Imagined publics and engagement around renewable energy technologies in the UK. Public Underst. Sci. 2010, 21, 36-50. [CrossRef] 
24. Jasanoff, S.; Kim, S.-H. Sociotechnical Imaginaries and National Energy Policies. Sci. Cult. 2013, 22, 189-196. [CrossRef]

25. Ballo, I.F. Imagining energy futures: Sociotechnical imaginaries of the future Smart Grid in Norway. Energy Res. Soc. Sci. 2015, 9, 9-20. [CrossRef]

26. Longhurst, N.; Chilvers, J. Mapping diverse visions of energy transitions: Coproducing socio-technical imaginaries. Sustain. Sci. 2019, 14, 973-990. [CrossRef]

27. Geels, F.W. Technological transitions as evolutionary reconfiguration processes: A multi-level perspective and a case-study. Res. Policy 2002, 31, 1257-1274. [CrossRef]

28. Pellizzoni, L. Energia di comunità. Una ricognizione critica della letteratura. In Energia e Innovazione tra Flussi Globali e Circuiti Locali; Osti, G., Pellizzoni, L., Eds.; EUT: Trieste, Italy, 2018.

29. Star, S.; Griesemer, J. Institutional ecology, 'translations' and boundary objects: Amateurs and professionals in Berkeley's Museum of Vertebrate Zoology, 1907-1939. Soc. Stud. Sci. 1989, 19, 387-420. [CrossRef] 